\title{
Rozwój topników do lutowania twardego
}

\author{
Development of fluxes for brazing
}

\section{Streszczenie}

Omówiono tendencje rozwoju nowoczesnych topników do lutowania twardego oraz topniki opracowane i wytwarzane dotychczas w Instytucie Spawalnictwa w Gliwicach. Opisano badania nad nowymi topnikami do lutowania twardego materiałów trudno lutowalnych - tytanu i stali nierdzewnej, a także właściwości lutownicze nowo opracowanych topników oraz jakość i właściwości połączeń lutowanych wykonanych z ich użyciem.

\section{Wstęp}

Podstawowym warunkiem zwilżenia lutowanych materiałów przez ciekłe spoiwo i utworzenia połączenia lutowniczego jest wysoka czystość łączonych powierzchni oraz lutu. Taką czystość można uzyskać np. stosując odpowiedni topnik lutowniczy, którego podstawowym zadaniem jest usunięcie warstw tlenkowych oraz właściwe zabezpieczenie lutowanych elementów podczas całego procesu lutowania.

Topniki lutownicze obok spoiw (lutów) oraz atmosfer kontrolowanych (atmosfer ochronnych), zaliczane są do grupy dodatkowych materiałów lutowniczych, których zastosowanie $w$ procesie lutowania warunkuje uzyskanie połączeń o wymaganych właściwościach eksploatacyjnych oraz dobrej jakości $[7 \div 9]$.

W Instytucie Spawalnictwa od przeszło 25 lat prowadzone są prace nad opracowywaniem nowych lub modyfikacją już istniejących składów recepturowych topników lutowniczych (opracowano dotychczas kilkanaście rodzajów topników). W ostatnich latach opracowano i wdrożono do produkcji laboratoryjnej następujące topniki do lutowania twardego $[3,4,14,15]$ :

- niskofluorkowe F6B (z amorficznym borem) oraz F10, przeznaczone do lutowania stali nierdzewnych (chromowych, chromowo-niklowych) oraz stopów miedzi (mosiądzów),

- wysokoaktywny topnik F60T do lutowania tytanu w atmosferze powietrza.

Dr inż. Dawid Majewski, dr inż. Andrzej Winiowski, prof. IS - Instytut Spawalnictwa, Gliwice

\section{Abstract}

Described trends in the development of modern brazing fluxes. Fluxes developed and produced in the Institute of Welding in Gliwice. Research into new fluxes for difficult brazing materials-titanium and stainless steel. Brazing properties of the newly developed fluxes and the quality and properties of joints made by them.

Wszystkie topniki do lutowania twardego opracowane w Instytucie Spawalnictwa są wytwarzane bezpieczną ekologiczną metodą przemiału mokrego w zamkniętych młynach kulowych. Są udostępniane w postaci trwałych past wodnych.

\section{Topniki do twardego lutowania stali nierdzewnych i stopów miedzi}

Do najczęściej stosowanych materiałów podstawowych na odpowiedzialne konstrukcje lutowane zalicza się stale wysokostopowe - nierdzewne, a wśród stopów miedzi - mosiądze. Lutowność tych materiałów jest zróżnicowana, zależnie od ich składu chemicznego oraz od rodzaju tlenków występujących na ich powierzchniach. Z uwagi na występowanie stosunkowo trwałych tlenków (tlenki chromu, niklu, molibdenu, aluminium, tytanu itp. - w przypadku stali wysokostopowych; tlenki cynku, ołowiu - w przypadku mosiądzów zwłaszcza ołowiowych), materiały te przed lutowaniem wymagają dokładnego oczyszczenia łączonych powierzchni (czyszczenie mechaniczne lub trawienie chemiczne) oraz w przypadku lutowania w powietrzu zastosowania odpowiednio aktywnego

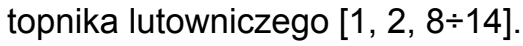

Jak już wspomniano we wstępie, do najważniejszych zadań, jakie spełniać musi topnik lutowniczy, należą: redukcja chemiczna i rozpuszczanie istniejących warstw tlenkowych na powierzchni materiałów łączonych lutu, a także zapobieganie ponownemu ich utlenieniu w czasie lutowania. Ponadto, odpowiednio dobrany 
topnik lutowniczy powinien również zmniejszać napięcie powierzchniowe lutu. Topnikom stawiane są liczne

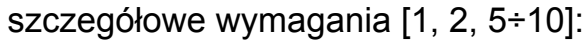

- temperatura topnienia i aktywności (temperatury te na ogół się pokrywają) nieco niższa od temperatury topnienia lutu, a temperatura parowania odpowiednio wyższa od tej temperatury,

- równomierne rozpływanie się w temperaturze lutowania po łączonych powierzchniach materiałów i dobre wnikanie do kapilarnych szczelin lutowniczych,

- skuteczna aktywność chemiczna w temperaturze lutowania i nieco poniżej oraz zdolność wiązania tlenkowych związków niemetalicznych na powierzchniach łączonych materiałów i lutu,

- ochrona złącza przed działaniem gazów atmosfery procesu (powietrza),

- tworzenie łatwo usuwalnego żużla i pozostałości topnikowych, wypływających na powierzchnię ciekłego lutu w trakcie powstawania połączenia lutowanego,

- trwałość składu chemicznego i postaci w warunkach magazynowania,

- zapewnienie możliwie najkorzystniejszych warunków bhp podczas lutowania,

- zastosowanie w składzie recepturowym topnika związków, które w nieznacznym stopniu wpływają na degradację środowiska naturalnego.

Lutowanie twarde stali wysokostopowych i mosiądzów prowadzi się obecnie najczęściej w atmosferze powietrza z użyciem lutów srebrnych i odpowiednio wysokoaktywnych topników lutowniczych. Dostępny asortyment tych topników jest duży, są to jednak głównie topniki wysokofluorkowe, gdyż tylko one zapewniają odpowiednią aktywność podczas procesu lutowania. W tablicy I podano przykładowe, typowe składy takich topników, wytypowane w wyniku analizy literaturowopatentowej [1, 2, 9].

Przedstawione składy recepturowe topników zawierają znaczne ilości toksycznych fluorków litowców. Obecnie, w gospodarkach wysoko uprzemysłowionych krajów, panuje tendencja odchodzenia od stosowania toksycznych oraz szkodliwych związków chemicznych w składach recepturowych topników do lutowania twardego i zastępowania ich równie aktywnymi, lecz mniej toksycznymi substancjami. Przykładem może być zastępowanie tradycyjnie dotychczas stosowanego fluorku potasu mniej toksycznym fluoroboranem potasu. W ten sposób na rynku pojawiły się topniki do twardego lutowania stali wysokostopowych, które zawierają niewielkie ilości toksycznych fluorków lub są całkowicie ich pozbawione [1, 9, 14, 15].

W Instytucie Spawalnictwa od wielu lat prowadzone są prace nad specjalistycznymi wysokoaktywnymi topnikami do twardego lutowania lutami srebrnymi stali wysokostopowych i stopów miedzi (mosiądzów). W 1996 r. opracowano i wdrożono do produkcji bezfluorkowy topnik LUTOSIL [12]. Topnik ten nie zawiera fluorków litowców, ale procentowa zawartość w nim fluoroboranów wynosi ponad 50\%. Ponadto, jak wykazały prze-
Tablica I. Przykłady topników fluorkowych stosowanych do twardego lutowania spoiwami srebrnymi i mosiężnym $[9,14]$

Table I. Examples of fluoride fluxes used for brazing with silver and brass filler metals $[9,14]$

\begin{tabular}{|c|c|c|c|}
\hline \multirow[b]{2}{*}{ Lp. } & \multicolumn{2}{|c|}{ Skład topnika wag } & \multirow{2}{*}{$\begin{array}{l}\text { Zakres tempera- } \\
\text { tury aktywności, } \\
{ }^{\circ} \mathrm{C}\end{array}$} \\
\hline & Składniki & $\begin{array}{c}\text { Zawartość, } \\
\% \text { mas. }\end{array}$ & \\
\hline 1 & $\begin{array}{l}\mathrm{B}_{2} \mathrm{O}_{3} \\
\mathrm{KBF}_{4} \\
\mathrm{KF}\end{array}$ & $\begin{array}{l}25 \div 36 \\
22 \div 40 \\
35 \div 43\end{array}$ & $500 \div 900$ \\
\hline 2 & $\begin{array}{c}\mathrm{H}_{3} \mathrm{BO}_{3} \\
\mathrm{Na}_{2} \mathrm{~B}_{4} \mathrm{O}_{7} \cdot 10 \mathrm{H}_{2} \mathrm{O} \\
\mathrm{KF}(\mathrm{NaF}) \\
\mathrm{NaBF}_{4}\left(\mathrm{KBF}_{4}\right)\end{array}$ & $\begin{array}{l}20 \div 30 \\
20 \div 30 \\
20 \div 40 \\
15 \div 30\end{array}$ & $600 \div 900$ \\
\hline 3 & $\begin{array}{c}\mathrm{H}_{3} \mathrm{BO}_{3} \\
\mathrm{KF} \text { bezwodny }\end{array}$ & $\begin{array}{l}60 \\
40\end{array}$ & $550 \div 850$ \\
\hline 4 & $\begin{array}{l}\mathrm{H}_{3} \mathrm{BO}_{3} \\
\mathrm{KF} \\
\mathrm{KBF}_{4}\end{array}$ & $\begin{array}{l}25 \div 35 \\
35 \div 42 \\
25 \div 40\end{array}$ & $500 \div 850$ \\
\hline 5 & $\begin{array}{c}\mathrm{H}_{3} \mathrm{BO}_{3} \\
\mathrm{Na}_{2} \mathrm{~B}_{4} \mathrm{O}_{7} \cdot 10 \mathrm{H}_{2} \mathrm{O} \\
\mathrm{CaF}_{2} \\
\end{array}$ & $\begin{array}{l}35 \\
50 \\
15 \\
\end{array}$ & brak danych \\
\hline 6 & $\begin{array}{c}\mathrm{KBF}_{4} \\
\mathrm{Na}_{2} \mathrm{~B}_{4} \mathrm{O}_{7} \cdot 10 \mathrm{H}_{2} \mathrm{O}\end{array}$ & $\begin{array}{l}70 \\
30\end{array}$ & brak danych \\
\hline 7 & $\begin{array}{c}\mathrm{KBF}_{4} \\
\mathrm{KF} \\
\mathrm{H}_{3} \mathrm{PO}_{4}\end{array}$ & $\begin{array}{l}34 \\
33 \\
33 \\
\end{array}$ & brak danych \\
\hline 8 & $\begin{array}{c}\mathrm{H}_{3} \mathrm{BO}_{3} \\
\mathrm{Na}_{2} \mathrm{~B}_{4} \mathrm{O}_{7} \cdot 10 \mathrm{H}_{2} \mathrm{O} \\
\mathrm{KBF}_{4} \\
\mathrm{LiF}^{4}\end{array}$ & $\begin{array}{c}60 \div 80 \\
5 \div 25 \\
4 \div 10 \\
1 \div 5\end{array}$ & $870 \div 920$ \\
\hline
\end{tabular}

prowadzone obserwacje tego topnika, jego trwałość chemiczna w postaci pasty wodnej jest niewielka. Po paru miesiącach od wyprodukowania topnik ten krystalizuje i jego dalsze zastosowanie jest znacznie utrudnione. W 1999 r. opracowano kolejny topnik niskofluorkowy o nazwie handlowej F25 (zawartość fluorków ok. $25 \%$ wag.), również przeznaczony do lutowania stali wysokostopowych oraz stopów miedzi (mosiądzów) [11]. Topnik ten należy do średnio aktywnych, niskofluorkowych topników lutowniczych. Jednakże z uwagi na skomplikowany skład chemiczny wytwarzanie jego jest bardzo kłopotliwe.

\section{Topnik niskofluorkowy F6B $z$ amorficznym borem do lutowania stali nierdzewnych}

Spośród stali wysokostopowych nierdzewnych szczególnie trudno lutowalne są stale nierdzewne chromowe (o strukturze ferrytycznej), trudnozwilżalne 


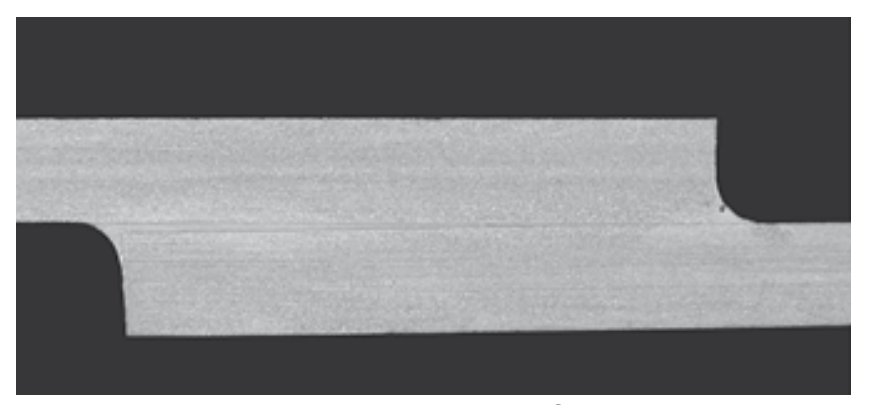

Rys. 1. Makrostruktura połączenia stali $\mathrm{X} 6 \mathrm{Cr} 17$ wykonanego lutem srebrnym Ag 244 i nowo opracowanym topnikiem niskofluorkowym F6B z borem, traw. odcz. Adlera

Fig. 1. Macrostructure of joints of steel $\mathrm{X} 6 \mathrm{Cr} 17$ made with silver braze grade Ag 244 and newly developed low-fluoride flux F6B containing boron, etch. Adler

przez luty srebrne. W dostępnej literaturze można znaleźć informację,że poprawę tego stanu może przynieść niewielki dodatek amorficznego boru do topnika fluorkowego przeznaczonego do lutowania tych stali. Powoduje on zwiększenie zakresu temperatur aktywności topnika (zarówno maksymalnej, jak i minimalnej), wydłużenie jego trwałości termicznej podczas procesu nagrzewania, a także wzrost aktywności [14]. Stwierdzono również, że sam bor nie jest wystarczającym dodatkiemi należy do topnika dodatkowo wprowadzić aktywatory w postaci przynajmniej jednego z następujących pierwiastków: Mo, W, Mn, Ni, Pd, Cu lub Ag - w postaci czystej lub stopu. Dodatkową korzyścią wynikającą z wprowadzenia boru do topników wysokofluorkowych jest możliwość obniżenia w nich zawartości toksycznych fluorków z zachowaniem wymaganej aktywności topnika, co w istotnym stopniu zmniejsza zagrożenia zdrowotne, jakim poddawany jest lutowacz [14].

Uwzględniając te spostrzeżenia, podjęto w Instytucie Spawalnictwa badania recepturowo-technologiczne nad topnikami fluorkowymi z borem i opracowano niskofluorkowy topnik tego typu. Połączenia zakładkowe stali X6Cr17 lutowane spoiwem Ag 244 (B-Ag44CuZn-675/735) wg PN-EN ISO 17672:2010 z użyciem tego topnika wykazały na podstawie badań metalograficznych i wytrzymałościowych dobrą jakość (rys. 1) oraz wysoką wytrzymałość na ścinanie wynoszącą ok. $200 \mathrm{MPa}$.

Końcowa wersja recepturowa nowo opracowanego topnika o przyjętej nazwie handlowej F6B zawiera korzystnie obniżony poziom fluorków do minimalnej zawartości wagowej $6 \div 8 \%$ oraz ok. $0,5 \%$ boru amorficznego.

\section{Topnik niskofluorkowy F10 do lutowania stali nierdzewnych i stopów miedzi}

Z uwagi na stosunkowo wysoką cenę topników lutowniczych zawierających w składzie recepturowym amorficzny bor (cena $1 \mathrm{~kg}$ amorficznego boru wynosi ok. 12000 zł), w 2012 r. w Instytucie Spawalnictwa opracowano kolejny niskofluorkowy topnik, charakteryzujący się wysokimi właściwościami lutowniczymi, pozbawiony jednakże amorficznego boru [14].

$\mathrm{Na}$ podstawie dotychczasowych doświadczeń nabytych w poprzednich pracach nad topnikami do lutowania twardego stali wysokostopowych jako osnowę nowego topnika zastosowano związki takie jak: tetraboran oraz pentaboran potasu. Analiza literaturowa oraz przegląd udokumentowanych wyników badań w zakresie opracowań topników do lutowania twardego umożliwiły wytypowanie do badań fluorków potasu (KF, $\mathrm{KHF}_{2}$ ) oraz tetrafluoroboranu potasu $\left(\mathrm{KBF}_{4}\right)$, jako akty-

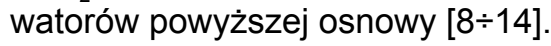

Pierwszy etap realizowanych badań nad nowym topnikiem polegał na opracowywaniu wariantów receptur próbek topnikowych, opartych na wytypowanych składach bazowych, sprawdzeniu ich temperatur topnienia i aktywności oraz ocenie zachowania się próbek podczas badań właściwości lutowniczych. Właściwości lutownicze próbnych wersji topnika oceniano na podstawie próby rozpływności spoiwa. Jako podłoże zastosowano płytki ze stali nierdzewnej X2CrNi18-9 (wg PN-EN 10088-1) oraz mosiądzu CW508L (CuZn37 wg PN-EN 1652). Spoiwo, którego rozpływność oceniano na powyższych materiałach przy obecności badanych topników, stanowił srebrny lut Ag 245 (B-Ag45CuZn-665/745) wg PN-EN ISO 17672. Wytrawione chemicznie próbki wraz $z$ ułożonym lutem i topnikiem podgrzewano od dołu stacjonarnym palnikiem acetylenowo-tlenowym.

Na podstawie przeprowadzonych prób do dalszych badań wytypowano topnik próbny, któremu nadano symbol F10, charakteryzujący się najkorzystniejszymi właściwościami lutowniczymi, który poddano bardziej szczegółowym badaniom w oparciu o próby wnikania w kapilarne szczeliny lutownicze, a także technologiczne próby lutowania złączy zakładkowych i ocenę jakości oraz właściwości mechanicznych tych połączeń. Ocenie poddano również trwałość konsystencji postaci pasty wodnej i właściwości lutowniczych topnika podczas magazynowania.

Próbne złącza zakładkowe ze stali nierdzewnej X2CrNi18-9 oraz mosiądzu CW508L, wykonane z użyciem topnika F10 i lutu srebrnego Ag 245, poddano badaniom metalograficznym i wytrzymałościowym. Złącza te lutowano płomieniowo w pozycji poziomej (płytki ułożone poziomo, swobodnie bez docisku, szerokość zakładki ok. $5 \mathrm{~mm}$, topnik w szczelinie lutowniczej i przy wylocie zakładki), dozując lut ręcznie u wylotu zakładki. Szerokość szczeliny lutowniczej ustalała się w tych warunkach samoczynnie $w$ trakcie wpływania lutu. Powyższa próba pozwala dodatkowo na dość ostrą ocenę właściwości kapilarnych lutu w obecności badanego topnika. Na rysunku 2 przedstawiono polutowane złącza zakładkowe, przygotowane do badań metalograficznych. Analizując rysunek 2, można zaobserwować wysoką aktywność topnika oraz skuteczne czyszczenie chemiczne w obszarze całego złącza. 
Na rysunkach 3 i 4 przedstawiono makrostruktury przekrojów poprzecznych połączeń. Złącza te nie wykazują jakichkolwiek niezgodności lutowniczych, zwłaszcza pustek, czy też pozostałości topnikowych. Ponadto zastosowanie tego topnika umożliwia otrzymanie gładkiego, pozbawionego niezgodności powierzchniowych lica lutowiny i właściwego kształtu wypływki pachwinowej u wylotu szczeliny lutowniczej.

Badania wytrzymałościowe połączeń wykazały, że charakteryzują się wysoką wytrzymałością. Średnia wytrzymałość połączeń na ścinanie wynosi 199 MPa.

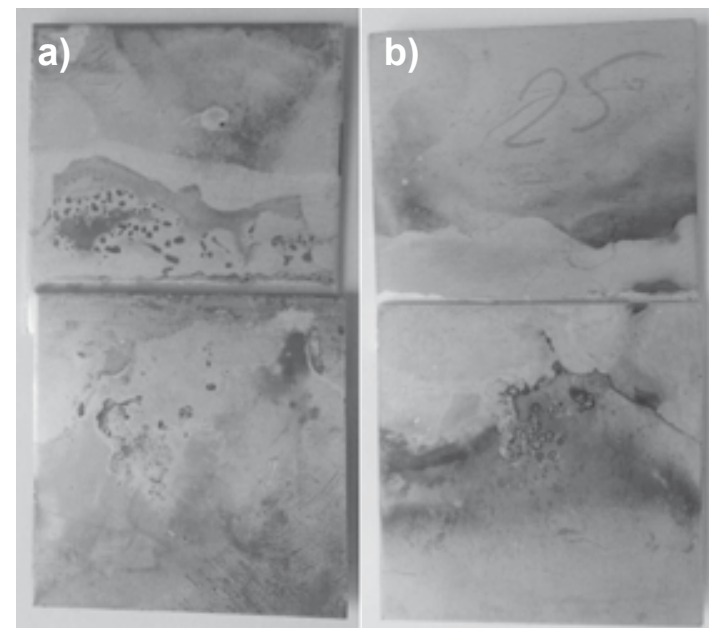

Rys. 2. Złącza zakładkowe do badań metalograficznych wykonane z zastosowaniem topnika F10 i lutu Ag 245 (szer. zakładki $5 \mathrm{~mm}$ ), mosiądz CW508L (a), stal nierdzewna X2CrNi18-9 (b)

Fig. 2. Lap joints for metallographic examinations carried out using of the F10 flux and braze Ag 245 (lenght of lap $5 \mathrm{~mm}$ ), brass CW508L (a), stainless steel X2CrNi18-9 (b)

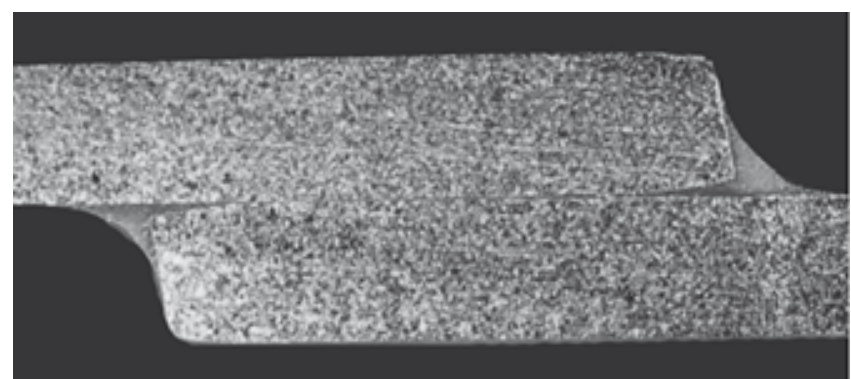

Rys. 3. Makrostruktura połączenia zakładkowego z mosiądzu CW508L wykonanego lutem srebrnym Ag 245 i topnikiem F10

Fig. 3. Macrostructure of brass overlap CW508L made by silver filler metal Ag 245 and flux F10

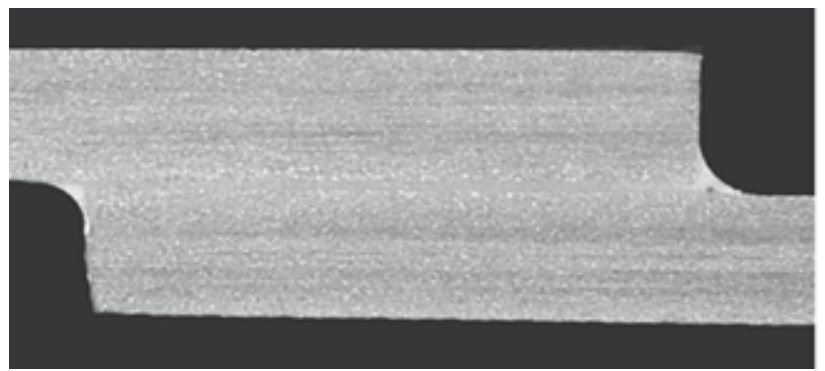

Rys. 4.. Makrostruktura połączenia zakładkowego ze stali nierdzewnej X2CrNi18-9, wykonanego lutem srebrnym Ag 245 i topnikiem F10 Fig. 4. Macrostructure of stainless steel overlap $\mathrm{X} 2 \mathrm{CrNi18}-9$ made by silver filler metal $\mathrm{Ag} 245$ and flux F10

\section{Topnik F60T do twardego lutowania tytanu w atmosferze powietrza}

Lutowność tytanu oraz jego stopów związana jest głownie z wysokim powinowactwem chemicznym tego reaktywnego metalu do innych pierwiastków, zwłaszcza gazów występujących w powietrzu, tj.: tlenu, azotu i wodoru. Podstawowym utrudnieniem procesu jego lutowania jest powstający podczas nagrzewania trwały tlenek $\mathrm{TiO}_{2}$. Intensywność powstawania tego tlenku jest szczególnie wysoka w zakresie temperatury $650 \div 700^{\circ} \mathrm{C}$, charakterystycznej dla lutowania lutami srebrnymi. W tej temperaturze na powierzchni tytanu powstaje niezwilżalna przez luty warstewka kruchego roztworu stałego z tlenem i azotem. Przy nagrzewaniu tytanu i jego stopów do temperatury powyżej $900^{\circ} \mathrm{C}$ w atmosferze powietrza, na ich powierzchni powstają również kruche azotki tytanu [3, 7, 9].

Lutowanie twarde podzespołów maszyn i urządzeń wykonanych z tytanu i jego stopów prowadzi się obecnie prawie wyłącznie w piecach $z$ atmosferami kontrolowanymi (czyste atmosfery neutralne chemicznie lub próżnia) [3, 4, 7, 8, 10]. Jednakże zachodzi niekiedy potrzeba polutowania niewielkich elementów z tego metalu na powietrzu (galanteria metalowa, obudowy lamp, oprawki okularów itp.). Mogą również wystąpić przypadki, gdy element tytanowy wymagający lutowania ma duże wymiary gabarytowe lub jest na stałe związany z większą konstrukcją (elementy instalacji). Wówczas istnieje możliwość prowadzenia procesu lutowania w atmosferze powietrza przy zastosowaniu:

- stosunkowo szybkiego (krótki czas procesu) nagrzewania płomieniowego lub indukcyjnego,

- spoiwa srebrnego,

- specjalistycznego, wysokoaktywnego chemicznie topnika.

Do procesu lutowania twardego tytanu w atmosferze powietrza jest niezbędny wysokoaktywny topnik lutowniczy. Większość topników zalecanych do lutowania różnych metali, nawet tych o najtrwalszych tlenkach, jest nieprzydatna w przypadku tytanu i jego stopów. Nie odtleniają one skutecznie powierzchni łączonych elementów, a także nie zapewniają właściwej ochrony tego reaktywnego metalu przed utlenieniem w temperaturze lutowania i w efekcie nie stwarzają prawidłowych warunków do zwilżenia powierzchni łączonych elementów stopionym lutem. W celu zapewnienia takiego działania topnik zastosowany do lutowania tytanu powinien spełniać przynajmniej jeden z podanych poniżej warunków [3, 4, 9]:

- usuwać niezwilżalną przez luty warstewkę tlenku i azotku tytanu przez absorpcję lub jej chemiczne roztwarzanie,

- oddziaływać aktywnie na powierzchnię metalu pod warstwą tlenków i azotków, przez co warstwa ta jest usuwana podczas płynięcia lutu.

Po spełnieniu tych warunków składniki topnika powinny w następnej kolejności wejść w reakcję z tytanem, wykorzystując jego zdolność do redukcji metali z roztopionych soli. Powierzchnia tytanu pokrywa się wówczas warstewką zredukowanego metalu, który zapobiega dalszemu utlenianiu $[3,4,9]$. 
Badania właściwości lutowniczych topnika prowadzono wg metodyki opracowanej i sprawdzonej we wcześniejszych pracach Instytutu Spawalnictwa nad topnikami, a więc opartej na klasycznej próbie rozpływności $[3,4,11 \div 15]$.

Spoiwo, którego rozpływność oceniano na próbkach tytanowych Grade 2 wg ASTM B265 przy obecności badanego topnika, stanowił lut srebrny Ag 245 (BAg45CuZn-665/745) wg PN-EN ISO 17672. Wytrawione chemicznie próbki tytanowe wraz $z$ ułożonym lutem i topnikiem podgrzewano od dołu stacjonarnym palnikiem acetylenowo-tlenowym. Podczas prób oprócz rozpływności lutu obserwowano również: przebieg topienia i spalania się składników topnika, czyszczenie chemiczne powierzchni płytki tytanowej przez topnik, temperaturę topnienia i rozpływności topnika, a także rodzaj i ilość powstającego żużla oraz łatwość jego usuwania. Dla finalnych najkorzystniejszych technicznie wersji topnika badania rozpływności uzupełniono próbami lutowania złączy zakładkowych i oceną metalograficzną ich jakości oraz właściwości mechanicznych. Ocenie poddano również trwałość konsystencji i właściwości lutowniczych topników. W wyniku badań stwierdzono, że najkorzystniejszy wpływ na właściwości lutownicze topnika spośród wszystkich wytypowanych związków chemicznych tworzących w trakcie lutowania na powierzchni tytanu warstwę ochronną przed utlenieniem, wykazuje topnik o symbolu F60T, zawierający w składzie recepturowym chlorek cynku (II).

\section{Wnioski}

Przeprowadzone badania recepturowe pozwoliły na opracowanie niskofluorkowych topników F6B i F10 do twardego lutowania lutami srebrnymi stali nierdzewnych (chromowych i chromowo-niklowych) oraz stopów miedzi (mosiądzów), a także aktywnego i trwałego podczas przechowywania topnika F60T do lutowania tytanu w atmosferze powietrza.

Topniki - niskofluorkowe F6B i F10 do lutowania stali nierdzewnych i mosiądzu oraz wysokofluorkowy
Dla topnika F60T przygotowano połączenia zakładkowe z tytanu Grade 2 z zastosowaniem lutu srebrnego $\mathrm{Ag}$ 245. Na rysunku 5 przedstawiono makrostrukturę przekroju poprzecznego połączenia przy szerokości szczeliny lutowniczej wynoszącej 0,05 $\div 0,12 \mathrm{~mm}$. Przeprowadzone badania metalograficzne pokazują, iż możliwe jest prawidłowe wykonanie złączy zakładkowych wykonanych z tytanem z zastosowaniem lutu srebrnego oraz specjalistycznego topnika lutowniczego F60T. Topnik ten umożliwia otrzymanie gładkiego, pozbawionego niezgodności powierzchniowych lica lutowiny, przy szerokości zakładki $5 \mathrm{~mm}$. Wytrzymałość na ścinanie złączy lutowanych wynosiła średnio $163 \mathrm{MPa}$.

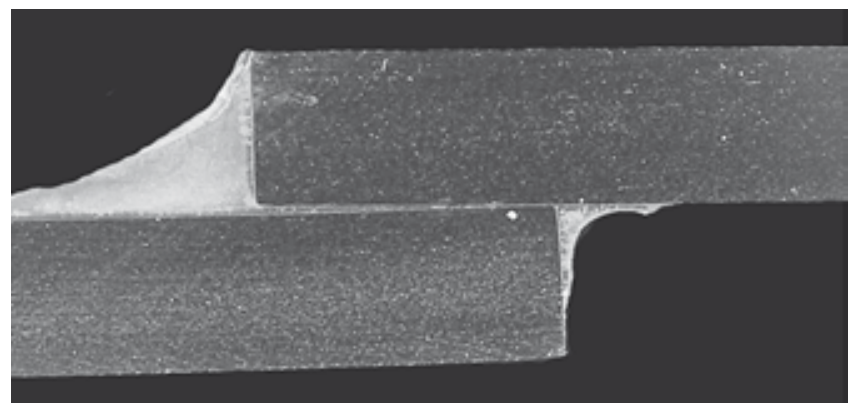

Rys. 5. Makrostruktura połączenia tytanu Grade 2 wykonanego lutem srebrnym Ag 245 i nowo opracowanym topnikiem wysokofluorkowym F60T, traw. odcz. Adlera

Fig. 5. Macrostructure of joints of titanium Grade 2 made with silver braze Ag 245 and newly developed high-fluoride flux F60T, etch. Adler

F60T do lutowania tytanu na powietrzu, charakteryzują się dobrymi właściwościami lutowniczymi, potwierdzonymi pozytywnymi wynikami prób rozpływności i technologicznych prób lutowania złączy próbnych z użyciem spoiwa srebrnego.

Połączenia stali nierdzewnej, chromowej X6Cr17, chromowo-niklowej X2CrNi18-9, mosiądzu CW508L i tytanu Grade 2 lutowane spoiwem srebrnym, odpowiednio z użyciem nowo opracowanych topników, wykazały wysoką jakość oraz wytrzymałość na ścinanie.

\section{Literatura}

[1] Baskin Y., Bemis L.: Effective Brazing Using Safer Fluxes, WeIding Design and Fabrication, July 2003.

[2] Łaško N.F., Łaško S.V.: Pajka metałłov. Mašinostrojenie, Moskva. 1984.

[3] Majewski D.: Lutowanie tytanu w atmosferze powietrza, Inżynieria Materiałowa $\mathrm{nr} 4$ (188), 2012.

[4] Mirski Z., Majewski D.: Lutowność tytanu w warunkach płomieniowego lutowania twardego pod osłoną topnika, Przegląd Spawalnictwa $\mathrm{nr} 1 / 2013$, s. $3 \div 7$.

[5] Müller W., Müller J.U.: Löttechnik. DVS, Düseldorf, 1995.

[6] Pietrunin I. E.: Fiziko-chimičeskije processy pri pajkie. Wysšaja Skoła, Moskva, 1972

[7] Praca zbiorowa. Poradnik Inżyniera. Spawalnictwo. T. 1 i 2 , WNT. Warszawa 2004/2005.

[8] Praca zbiorowa: Brazing Handbook. AWS, Miami, Florida, 1991.

[9] Praca zbiorowa: Spravočnik po pajkie. Mašinostrojenie, Moskva. 2003.
[10] Schwartz M.: Brazing. Wyd. 2, ASM International, Materials Park, Ohio, 2003.

[11] Winiowski A., Lis U.,: Opracowanie niskofluorkowego topnika do lutowania spoiwami srebrnymi stali wysokostopowych. Praca Badawcza Instytutu Spawalnictwa nr Gn-7/ST-143,

[12] Winiowski A., Lis U.: Badania nad topnikami nisko- i bezfluorkowymi do lutowania twardego. Praca Badawcza Instytutu Spawalnictwa $\mathrm{nr}$ Cc-48/ST-92.

[13] Winiowski A., Lis U.: Studium i badania w zakresie lutowania metali i stopów. Praca badawcza Instytutu Spawalnictwa nr Gh-20/ST-73/1995.

[14] Winiowski A., Majewski D.: Nowe topniki do lutowania twardego stali nierdzewnych oraz tytanu i jego stopów, Biuletyn Instytutu Spawalnictwa, $\mathrm{nr}$ 6, 2008.

[15] Winiowski A., Majewski D.: Opracowanie niskofluorkowego topnika do twardego lutowania stali wysokostopowych i mosiądzu, Zadanie badawcze nr Cc-53/2, Instytut Spawalnictwa, Gliwice 2012. 